DOI: http://dx.doi.org/10.18569/tempus.v10i3.1763

\title{
Atenção Primária à Saúde: espaço potencial de criatividade.
}

\section{Primary Health Care: potencial field for creativity.}

\section{Atención Primaria de la Salud: espacio potencial de creatividad.}

.Magda Duarte dos Anjos Scherer ${ }^{1}$ Erica Lima Menezes ${ }^{2}$

RESUMO: Nesse artigo discute-se a atenção primária à saúde no Brasil como espaço potencial de criatividade, favorecido pela implantação de um novo modelo de atenção. Apresentam-se expressões da criatividade no trabalho, entendendo-as como um processo social participativo originado a partir das potências locais, onde indivíduos agem integrados a coletivos de trabalho, movidos por desconforto intelectual que os impulsiona a enfrentar os constrangimentos do meio e a encontrar as reservas de alternativas presentes no contexto.

Palavras-chave: Trabalho. Atenção Primária à Saúde. Criatividade.

ABSTRACT: This paper study the primary health care in Brazil as a potential field for creativity favoured by the implementation of a new model of health care. It presents expressions of creativity at work defined as an participatory social process rooted in the local possibilities, inwhich individuals actions are integrated to work teams and are motivated by an intelecual discomfort that move them to face environmental constraints and to find reserves of alternatives available in the context.

Keywords: Work. Primary Health Care. Creativity.

RESUMEN: En este artículo se discute la atención primaria de la salud en Brasil como un espacio potencial de creatividad, favorecido por la implementación de un nuevo modelo de atención. Se presentan expresiones de creatividad en el trabajo, entendiéndolas como un proceso social participativo originado a partir de las potencias locales, donde los individuos actúan integrados a colectivos de trabajo, movidos por una incomodidad intelectual que los impulsa a enfrentar las limitaciones del medio y encontrar las reservas alternativas presentes en el contexto.

1Universidade de Brasília(UnB). Departamento de Saúde Coletiva. Brasíli - DF. Brasil. E-mail: magdascherer@unb.br 2Universidade Federal de Santa Catarina. E-mail: ericalcmenezes@gmail.com

Publicado com a gentil autorização da Revue Education Permanente. www.education-permanente.fr 
Palabras clave: Trabajo. Atención Primaria de la Salud. Creatividad.

\section{INTRODUÇÃO}

A saúde, na Constituição brasileira de 1988, está associada a condições de vida, sendo um direito de cidadania e dever do Estado garantido por meio de políticas econômicas e sociais. Nesse sentido, em 1990 foi instituído o Sistema Único de Saúde (SUS) tendo como princípios a universalidade no acesso, a integralidade da atenção, a igualdade da assistência e a participação da população na tomada de decisão sobre os serviços de saúde.

O novo sistema de saúde surgiu como resposta ao desafio de oferecer serviços resolutivos e de qualidade, num momento de crise econômica e social, somado à transição demográfica e epidemiológica, resultante do envelhecimento da população. Diversos problemas precisavam ser enfrentados: desigualdades regionais e sociais; aumento das doenças crônicas com convivência das transmissíveis; crescimento da mortalidade por doenças cardiovasculares, câncer e causas externas, entre outros; persistência de um modelo assistencial biomédico e centrado no hospital que se ocupava fundamentalmente da doença e do indivíduo isolado do seu contexto de vida. No âmbito do sistema de saúde, essa problemática passou a ser enfrentada com grande investimento público na estruturação da atenção primária à saúde (APS).

A atenção primária é um conjunto de ações de saúde no âmbito individual e coletivo que abrangem a promoção e proteção da saúde, prevenção de agravos, diagnóstico, tratamento, reabilitação e manutenção da saúde. Essas ações são realizadas por equipes multiprofissionais compostas por médicos, enfermeiros, dentistas, técnicos de enfermagem e de saúde bucal, bem como agentes comunitários de saúde, responsáveis por um número determinado de famílias num determinado território. No contexto brasileiro, o modelo de APS que vem sendo implantado como política de Estado desde 2006 é chamado Estratégia Saúde da Família (ESF).

São novas políticas, novos regulamentos e protocolos a serem aplicados nacionalmente, em cada município e para cada usuário, num país continental como o Brasil, com grande diversidade e desigualdades, o que coloca uma série de desafios para o trabalho dos profissionais. Como fazer a gestão da distância entre as normas antecipadoras do trabalho e as possibilidades que o meio oferece? Como aprender a ser eficaz? Como fazer para que o trabalho venha em benefício da produção da saúde dos outros e de si mesmo?

Um contexto como o apresentado acima exige uma reinvenção cotidiana do fazer em saúde e faz um apelo à criatividade.

Embora a criatividade seja um termo polissêmico, há um consenso de que se trata de uma característica inerente ao ser humano ${ }^{1,2}$. Desde os primórdios, a humanidade tem usado o seu potencial criativo para modificar o ambiente ao seu redor, transformando-o assim em um espaço que atenda às suas necessidades, quaisquer que sejam elas ${ }^{3}$, sendo que a produção criativa é 
resultante de um conjunto de fatores individuais, sociais, culturais e relacionados ao ambiente no qual o sujeito encontra-se inserido ${ }^{4}$.

É difícil precisar e dimensionar a criatividade em função da multiplicidade de elementos que concorrem para a sua manifestação. Um ambiente pode favorecer ou limitar a criatividade. Os trabalhadores vão ter maneiras distintas de lidar com este ambiente? O que seria um ambiente favorecedor da criatividade?

Discutimos aqui a criatividade como sendo um processo social participativo originado a partir das potências locais, onde indivíduos agem integrados a coletivos de trabalho, movidos por desconforto intelectual que os impulsiona a enfrentar os constrangimentos do meio e a encontrar as reservas de alternativas presentes no contexto ${ }^{5}$. Um ambiente comporta sempre, em graus variáveis, limites e potencialidades à criatividade, que serão geridas pelos indivíduos e grupos, em meio a um debate de normas e de valores que está presente em toda situação de trabalho.

Nesse sentido, na primeira parte deste texto apresentamos a atenção primária à saúde no Brasil como espaço potencial de criatividade, e na segunda, trazemos expressões da criatividade no cotidiano do trabalho coletivo na APS.

\section{ATENÇÃO PRIMÁRIA - AMBIENTE FAVORÁVEL À CRIATIVIDADE}

A APS é o contato preferencial dos usuários com o sistema de saúde, utiliza tecnologias de elevada complexidade e baixa densidade, e deve resolver os problemas de saúde de maior frequência e relevância em seu território, integrando-se a uma rede de serviços especializados. Para implementar o novo modelo a política nacional brasileira define as características do processo do trabalho e as atribuições das equipes e dos profissionais: devem realizar cuidado na unidade, no domicílio e nos espaços comunitários; identificar necessidades e riscos; fazer planejamento e monitoramento das ações e das condições de saúde da população; construir vínculo entre si e com os usuários; buscar efetivar o controle social e a intersetorialidade, entre outros.

A APS se orienta pela concepção de que saúde é um processo relacionado a determinantes sociais e econômicos. As equipes multiprofissionais devem articular saberes técnicos e populares, bem como mobilizar recursos necessários para o enfrentamento dos problemas de saúde. São responsáveis pelo cuidado individual, pelas famílias e pela coletividade. Devem acolher as necessidades da população, priorizar situações de risco e contribuir para a autonomia das pessoas e coletividades apoiando-se na realização de ações capazes de dar respostas singulares e eficazes aos problemas de saúde.

Nesse contexto desafiador, a criatividade é um elemento-chave presente no cotidiano do trabalho, seja na relação dos profissionais com os usuários, na relação entre os próprios profissionais, como na organização e gestão do trabalho. A criatividade pode ser para os trabalhadores, motor e resultado: da busca de eficácia das ações; da proteção da própria saúde; do reconhecimento e valorização do 
seu trabalho, por si mesmo ou pelos outros; de maneiras de desenvolver o trabalho de forma mais prazerosa.

A literatura sobre a criatividade ${ }^{1,2,3,4}$ aponta que não apenas os fatores individuais influenciam a sua expressão e considera o ambiente social também como fator determinante, limitando ou potencializando. Entretanto, quem age são indivíduos e coletivos de acordo com as suas capacidades de enfrentamento do meio, que é sempre infiel, mas que sempre possui reservas de alternativas.

Consideramos que a APS tende a configurar-se como ambiente propicio à expressão da criatividade dos coletivos de trabalho, comportando duas grandes dimensões que interatuam de maneira a favorecer o agir criativo dos profissionais: a dimensão das normas antecedentes e a dimensão das condições de trabalho dos profissionais e de vida da população usuária dos serviços de saúde.

\section{A primeira dimensão}

O conjunto das normas antecedentes para o trabalho na APS favoreceria a criatividade pela implantação em curso do modelo assistencial Estratégia Saúde da Família, considerado uma inovação tecnológica de organização do trabalho do tipo incremental. Inovação por adicionar novas ações assistenciais com método organizacional não utilizado anteriormente no modelo tradicional pautado no paradigma positivista centrado na cura da doença, no atendimento hospitalar e na figura do profissional médico como o detentor do saber em saúde. Incremental por não romper totalmente com as práticas do modelo tradicional ${ }^{6}$.

A organização do trabalho a partir das necessidades de saúde da população e em equipes multiprofissionais se configura como um desafio e também um potente fator de produção de espaços criativos. Desafiador por exigir a superação do trabalho fragmentado em Núcleos profissionais, e ao mesmo tempo por exigir a constituição de um Campo comum de atribuições coletivas. Por Núcleo entender-se-ia o conjunto de saberes e de responsabilidades específicos de cada profissão ou especialidade. [...] Por Campo ter-se-iam saberes e responsabilidades comuns ou confluentes a várias profissões ou especialidades ${ }^{7}$. O Campo seria um espaço onde cada disciplina e profissão se apoiaria nas outras para dar conta das suas tarefas teóricas e práticas, sendo um espaço de limites imprecisos. Tanto o Núcleo como o Campo se interinfluenciam e estão em mutação ${ }^{8}$.

O trabalho coletivo que se estabelece nesse processo pode fomentar espaços de inclusão, de participação e de aprendizagem, e a criação de ações alternativas e complementares à prática biomédica, reconfigurando práticas, saberes e valores, com grande potencial criativo nas formas de entender e realizar o cuidado.

A vinculação da equipe de saúde a cerca de 3500 pessoas numa determinada área geográfica possibilita que os profissionais conheçam as necessidades de saúde do seu território, façam o confronto dessas necessidades com as ações que desenvolvem, e possam se reposicionar para 
qualificar sua atuação. Uma parte expressiva das demandas apresentadas pelos usuários na Atenção Primária não respondem a uma terapia medicamentosa exclusiva e apresentam "sintomas vagos e difusos", "sintomas físicos e/ou psíquicos múltiplos, que geram sofrimento nas pessoas e sobrecarregam os serviços de saúde, sem um diagnóstico anatomopatológico correspondente" 9. Esse contexto exige que os trabalhadores busquem alternativas que associem o conhecimento que emerge do contato com a comunidade com aquele oriundo da formação das diferentes categorias profissionais, em confronto com o conjunto de materiais, manuais e normas disponíveis para orientar o agir. As equipes, dessa forma, são tensionadas a enxergarem os problemas de um novo ângulo, o que possibilita pensar também novas respostas para os problemas que anteriormente eram "resolvidos" de forma fragmentada, a partir do olhar médico.

Fortalecer a participação popular e o controle social também é uma das normas para o trabalho na APS. O conhecimento das necessidades, dos modos de vida, bem como das potencialidades e limites do território, deve ser feito com a participação da população. Assim, são estabelecidas redes de atuação, que abrem espaço para que ideias criativas sejam mais facilmente colocadas em prática. As redes criativas se configuram de forma singular, a partir e no momento da realização da atividade ${ }^{10}$.

\section{A segunda dimensão}

Nos últimos anos, o Brasil tem vivido importantes avanços econômicos e sociais, entretanto ainda resta, entre outros, o desafio de reduzir as iniquidades sociais e de qualificar o sistema de saúde. A implantação das equipes da atenção primária aconteceu em contextos muito distintos, com variação no ritmo e na proporção entre as regiões brasileiras ${ }^{11}$. Muitas equipes de saúde atuam em estruturas físicas precárias, com falta de material, péssimas condições de trabalho, vínculos empregatícios precários, números de pessoas a acompanhar que extrapola o preconizado, e financiamento insuficiente.

O ambiente de trabalho nem sempre contribui para a aplicação das normas. Ao mesmo tempo, as desigualdades sociais e econômicas na sociedade brasileira limitam a eficácia das ações em saúde e clamam por atuação intersetorial, ou seja, por integração do trabalho profissional em saúde com o de outras áreas de atuação, como a assistência social, educação, habitação, entre outras. Somemse ainda as exigências de incorporação de novas tecnologias e a convivência diária com a dor e a morte, gerando sofrimento para o trabalhador.

O sofrimento pode ser criativo quando o indivíduo o transforma em algo benéfico para ele e para os demais, quando se motiva e se sente desafiado a produzir ações que são produtivas para ele e para a sociedade ${ }^{12}$. Em alguns casos, a escassez de recursos, equipamentos e insumos pode estimular o fazer criativo, ampliando a escuta e promovendo vínculo entre profissionais e usuários. Dessa forma, o uso da criatividade passa a ser uma função do cotidiano das práticas de saúde, no qual trabalhadores da atenção primária seriam permanentemente provocados a buscar novas 
maneiras de enfrentar as dificuldades que surgem no dia a dia do trabalho.

\section{EXPRESSÕES DA CRIATIVIDADE NA ATENÇÃO PRIMÁRIA}

O cenário da atenção primária no Brasil pode parecer, à primeira vista, pouco fértil a ações criativas, mas a complexidade do processo saúde-doença tem mobilizado trabalhadores, em função da urgência de eficiência e eficácia, a pensar maneiras de produzir cuidado de qualidade e de vivenciar menos sofrimento no trabalho.

Diversas equipes têm inventado formas de tornar os ambientes mais acolhedores buscando romper com o imaginário dos usuários de que os Centros de Saúde são espaços onde prevalecem a doença, o sofrimento e a dor. Outras buscaram alternativas de fazer o cuidado.

Nesse sentido, apresentamos três experiências, retiradas da literatura, que expressam a criatividade no trabalho na APS: a "Tenda do conto"; "Um olhar para além da demanda" e o "Portal das artes".

\section{A Tenda do conto}

Uma Unidade de Saúde da Família, na cidade de Natal, Nordeste do Brasil, criou a Tenda do Conto, experiência que utiliza a contação de histórias para promover o protagonismo e corresponsabilização de usuários e trabalhadores do SUS, enfrentar a desmotivação e fragmentação do trabalho com escuta, discussão e arte, incluindo na produção de saúde as histórias de vida de trabalhadores e usuários. A ideia da tenda surgiu da percepção de que a população inventa formas de enfrentamento da carência e isolamento da região, e que muitas delas não eram levadas em conta pelo serviço. Em um primeiro momento criaram um filme para que parte destas histórias pudessem ser contadas e em um segundo momento, como meio de ampliar essa participação criaram a Tenda do Conto. Transformaram a sala de reuniões da unidade em uma "sala de estar". Na mesa toalha rendada e objetos trazidos pelos profissionais e usuários (uma velha lamparina a querosene, um ferro de passar a carvão, uma chaleira, um rádio, um porta-retratos), na parede, um estandarte de retalhos coloridos exibe versos, mensagens, fragmentos afixados de antigas conversas. Completando a cena, uma cadeira de balanço coberta por uma manta de algodão espera pelo próximo que irá sentar e contar sua história ${ }^{13}$. Com criatividade, os trabalhadores fortaleceram o vínculo com os usuários e transformaram a Unidade de Saúde em local não apenas de cura da doença, mas, sobretudo de promoção da saúde.

\section{Um olhar para além da demanda}

No município de João Pessoa, Paraíba, Brasil, estratégias desenvolvidas por profissionais de saúde para produzir novas formas de cuidado, alternativas ao modelo biomédico hegemônico, demonstram o potencial criativo existente nos territórios da atenção primária. Ao perceber o constrangimento de um usuário ao não saber escrever o próprio nome, a equipe organiza cursos de 
alfabetização de adultos como forma de inclusão social. Considerando as demandas da comunidade e a pluralidade de saberes que contribuem para a compreensão e intervenção na saúde, foi aberto um espaço para as rezadeiras, buscando valorizar o saber popular e a reapropriação, no Centro de Saúde, de práticas negadas historicamente no processo de medicalização da vida pelos saberes oficiais. Para evitar, em algumas situações, encaminhamento de usuários a outros níveis de atenção ou evitar a prescrição de medicamentos desnecessários e ineficientes, um profissional começou a estudar a fisiologia da dor e passou a oferecer massagem como modo de cuidar até então inexistente no cardápio de ações ofertadas pelos serviços de atenção primária ${ }^{14}$.

\section{Portal das artes}

O Sr. Anésio tinha 74 anos e ia com frequência à unidade de saúde apresentando queixas que deixavam a equipe com a sensação de impotência, pois ele estava medicado e com a pressão arterial controlada, mas seu quadro depressivo se mantinha inalterado. A equipe fez uma reunião com a presença de uma psicóloga e concluíram que a terapia até então estabelecida para o Sr. Anésio não respondia às suas necessidades. Decidiram fazer uma visita a casa do usuário e na conversa e observação viram que havia sido marceneiro durante muitos anos, que tinha muita habilidade com a madeira e que seus olhos brilhavam quando contava suas histórias de marcenaria. Propuseram então que ele começasse a dar aulas de marcenaria para adolescentes da comunidade e transformaram a varanda da casa dele em uma escola-marcenaria. O projeto cresceu, a equipe identificou outras potencialidades na comunidade. Buscou apoios externos à unidade para viabilizar novas ações. Acionaram o Conselho Gestor Local e organizaram várias frentes de trabalho em parcerias com instituições públicas e privadas. Visitaram também entidades da comunidade (grupos de jovens, de mulheres, times de futebol, associações de bairro, etc.), sempre buscando estabelecer conexões e atuar em rede. Assim nasceu o Portal das Artes. Foram organizadas várias atividades: além da marcenaria, cursos de artesanato, de línguas, atividades lúdicas, de relaxamento, de musica, etc. Vários profissionais de saúde das unidades próximas passaram a realizar no Portal das Artes ações de saúde distintas daquelas que faziam no cotidiano da unidade básica de saúde, sentindo mais prazer no seu trabalho. A maioria das ações era realizada por usuários-professores para usuários-aprendizes ${ }^{15}$.

\section{O QUE AS EXPERIÊNCIAS NOS DIZEM SOBRE A CRIATIVIDADE}

\section{A criatividade é uma necessidade}

As experiências sugerem que a criatividade surge da necessidade presente nos contextos de vida, associado às normas antecedentes favoráveis. É como se houvesse "permissão" no espaço para a reinvenção do cotidiano de trabalho. Uma situação comum nos serviços de saúde no Brasil é a excessiva demanda em relação à oferta, a qual muitas vezes não responde às queixas dos usuários, mesmo após uma consulta médica, realização de exames ou consumo de medicamentos. As experiências sinalizam que os profissionais são capazes de romper com o isolamento e inventar 
novas formas de trabalhar que extrapolem as paredes das unidades. A grande demanda e a baixa eficácia das ações tradicionais produzem uma pressão nas equipes e a sensação de impotência, que mobilizam o agir criativo. As normas heterodeterminadas são generalizantes, feitas em desaderência dos territórios locais, deixando aos profissionais a necessidade de encontrar os modos de aplicalas segundo as singularidades locais. Nesse sentido, eles não se restringem à organização formal do trabalho ou ao que está no organograma, buscam diversos recursos no território e estabelecem conexões singulares, conformando a atuação em rede.

\section{A criatividade pressupõe desconforto intelectual}

A produção de novas formas de cuidado revela a postura de desconforto intelectual dos profissionais diante de um meio que solicita para agir. A criatividade "emerge em momentos de cuidado muito particulares, quando os profissionais exercitam um olhar que enxerga além do que lhes é apresentado explicitamente como demanda por cuidados de saúde" ${ }^{14}$, convivendo com diversas racionalidades. Nesse contexto a criatividade surge construindo novas normas resultantes da atividade, demonstrando a capacidade dos profissionais de ir além do que convencionalmente se conhece como cuidado.

\section{A criatividade é orientada por valores}

No debate de normas e valores presente na atividade, as escolhas parecem ter sido orientadas por valores de defesa da vida: da saúde como direito de todos e dever do estado; da garantia de acesso aos cuidados de saúde; da valorização dos saberes da experiência dos usuários; do direito do usuário de participar da decisão do seu processo terapêutico. Olhar o outro como um ser semelhante e construir o trabalho reconhecendo a diversidade de saberes presente no contexto são valores que tendem a orientar para a produção de formas distintas e singulares de fazer saúde.

\section{O conhecimento favorece a criatividade}

Ao conhecer as necessidades e reservas de alternativas, presentes no território, os coletivos se permitem improvisar, distrair-se, autorizar-se. O conhecimento não só do território, mas também das normas antecedentes, da experiência gerada no e pelo trabalho, e das lacunas de normas que despertam o desejo do profissional de estudar para se apropriar de novas tecnologias para ser eficaz, parece ser um ingrediente a favorecer a criatividade.

\section{OS PROFISSIONAIS AUTORIZAM-SE A CRIAR}

Profissionais e usuários se autorizaram criar a partir da escuta das necessidades do território. Em certas situações percebem que a escuta individual não seria possível para todos e improvisam uma escuta coletiva. Improvisar pode ser favorecido pela autonomia do profissional e pelo reconhecimento, por parte do usuário, do trabalho do profissional. A resposta do usuário, reconhecendo e valorizando o novo, poderia ser um elemento favorecedor da criatividade. $\mathrm{O}$ 
trabalho em saúde se configura como ações realizadas por coletivos que são capazes de inventar e reinventar modos de fazer também se transformando - a si próprios e aos coletivos ${ }^{16}$. No caso da saúde, onde o "objeto" do trabalho não é um "paciente", mas um sujeito, este influencia diretamente no modo de fazer o cuidado, potencializando ou constrangendo o agir criativo.

\section{REFERÊNCIAS BIBLIOGRÁFICAS}

1. Winnicott DW. Vivendo de modo criativo. In: Tudo começa em casa. São Paulo: Martins Fontes, 1989.

2. De Mazi D. Criatividade e grupos criativos. Rio de Janeiro: Sextante, 2003.

3. Vygotski LS La imaginacion y el arte en la infancia. Madrid: Akal, 1990.

4. Alencar EMLS, Fleith DS. Barreiras à promoção da criatividade no ensino fundamental. Psic. Teor. e Pesq. 2008; 24(1):59-65.

5. Schwartz Y. Le paradigme ergologique ou un métier de philosophe. Octares editions, 2000 .

6. Scherer MDA, Pires DEP, Soratto J. O trabalho na Estratégia Saúde da Família. In: Saúde da Família nos municípios brasileiros: os reflexos dos 20 anos no espelho do futuro. Campinas: Saberes Editora, 2014. p. 521-71.

7. Campos GW. Subjetividade e administração de pessoal: considerações sobre modos de gerenciar o trabalho em equipes de saúde. In: Merhy, Onocko (Org.). Agir em saúde: um desafio para o público. São Paulo/Buenos Aires: Hucitec/Lugar Editorial, 1997, p. 229-66.

8. Campos GW. Saúde pública e saúde coletiva: campo e núcleo de saberes e práticas. Ciênc. Saúde Coletiva. 2000; 5(2):219-30.

9. Ministério da Saúde (BR). Secretaria de Atenção à Saúde. Política Nacional de Humanização da Atenção e Gestão do SUS. Brasília: Ministério da Saúde, 2009. 40 p.

10. Schwartz Y. A dimensão coletiva do trabalho e as Entidades Coletivas Relativamente Pertinentes (ECRP). In: Schwartz Y, Durrive L. (Orgs.) Trabalho \& ergologia - conversas sobre a atividade humana. Niterói: EdUFF, 2007.

11. Silva LA, Casotti CA, Chaves SCL. A produção científica brasileira sobre a Estratégia Saúde da Família e a mudança no modelo de atenção. Ciênc. Saúde Coletiva. 2013; 18(1):221-32.

12. Dejours C, Abdoucheli E. Itinerário teórico em psicopatologia do trabalho. In: Dejours C, Abdoucheli E, Jayet C. Psicodinâmica do trabalho: contribuições da escola dejouriana à análise 
da relação prazer, sofrimento e trabalho. São Paulo: Atlas, 2009. p. 119-45.

13. Gadelha JA. Tenda do conto: cinco anos (a)colhendo histórias. [Internet] 2012. Disponível em: http://www.redehumanizasus.net/13378-tenda-do-conto-cinco-anos-acolhendohistorias. Acesso em: 06 fev 2013.

14. Oliveira AKS, Bezerra IMP, Silva CC, Lima Neto EA, Silva ATMC. Experiências alternativas resgatando saberes para os processos de trabalho em saúde. Rev Esc Enferm USP. 2012; 46(4):953-9.

15. Ministério da Saúde (BR). Secretaria de Atenção à Saúde. Política Nacional de Humanização da Atenção e Gestão do SUS. Brasília: Ministério da Saúde, 2010. 40 p.

16. Santos Filho SB. Um olhar sobre o trabalho em saúde nos marcos teórico políticos da saúde do trabalhador e do HumanizaSUS. 2007. Disponível em: http://bvsms.saude.gov.br/bvs/ publicacoes/olhar_sobre_trabalho.pdf. Acesso em: 02 jul 2015.

Artigo apresentado em 26/10/15

Artigo aprovado em 21/09/16

Artigo publicado no sistema em 10/10/16 